\title{
THE IMPACT OF THE INTERVIEWER-INTERVIEWEE RELATIONSHIP ON SUBJECTIVE QUALITY OF LIFE RATINGS IN SCHIZOPHRENIA PATIENTS
}

\author{
WOLFGANG KAISER \& STEFAN PRIEBE
}

\begin{abstract}
SUMMARY
Subjective quality of life (SQOL) ratings are usually based on interviews. This study examined in which way patients' ratings differ depending on whom they are interviewed by. SQOL was assessed in 78 schizophrenia patients in an out patient clinic and in sheltered living arrangements. Using patients randomly allocated to two interview situations: one group was interviewed by external researchers, the other group by their case managers. On average, more favourable ratings were elicited by case managers. Some of the differences were statistically significant and substantial in size. Yet, opposing differences were also found regarding some life domains in one group. It may be concluded that a significant impact of the interviewer-interviewee relationship on SQOL ratings may exist, but that it is not consistent, unidirectional and uniform regarding life domains and across different settings and samples.
\end{abstract}

\section{INTRODUCTHON}

In mental health care, the concept of subjective quality of life (SQOL) health was initially used for investigating the effects of deinstitutionalisation (Lehman, 1983; Lehman et al. 1986). These days it has become a more and more indispensable evaluation criterion for the whole spectrum of psychiatric care and treatment - whether it is confined to psychopharmacological treatment (Awad et al. 1999) or more complex care programmes in the community (Holloway \& Carson, 1988; Taylor et al. 1998). Methodological prerequisites to assess SQOL have been reported in reviews of SQOL-interview-instruments (Lehman, 1996; Oliver et al. 1997) and been the subject of specific methodological papers (Corrigan \& Buican, 1995; Kaiser \& Priebe, 1998; Kaiser, 1999; Priebe et al. 1999; Russo et al. 1997; Voruganti et al. 1998). Although most SQOL measures reported in the psychiatric literature are interview based, the issue of the interviewer effect has rarely been mentioned or investigated in studies and methodological papers to date.

Numerous studies have demonstrated that professional staff and patients may have very different views on a patient's quality of life ( Sainfort et al. 1996; Skantze et al. 1992; Thapa \& Rowland, 1989). Yet, the next step to investigate the implications of professional staff asking patients about their SQOL and to assess the influence of the interviewer on the patients' ratings has not been taken. This may be due to the fact that SQOL data as published in research papers have rarely been gathered as part of routine data collection. In most 
research studies, interviewers asking patients about their SQOL are independent researchers, who are not in any way involved in treatment or in the patient's care setting. When quality of life interviews are carried out in routine practice, however, professional staff obtain quality of life data the question of interviewer bias and interviewer effect becomes of crucial importance. This is independent of whether SQOL is assessed for the purpose of individual treatment planning or for evaluating a service (Priebe et al. 1999).

In a controlled study in Berlin, Kaiser et al. (1998) tested the influence of the interviewerinterviewee relationship on SQOL ratings: from all patients $(\mathrm{N}=186)$ from a catchment area of 220.000 population (district Spandau) who were living in sheltered community housing arrangements, a random sample was drawn and randomly assigned to two different interview conditions for assessing SQOL: one group (A) was interviewed by staff working for providers in the same district (most of them were social workers), but not known to the patients they interviewed and not involved in the care of the interviewees. The other group (B) was interviewed by their case managers. Patients in group B expressed a higher degree of satisfaction with their subjective quality of life: the overall mean value of SQOL $(p<.05)$ as rated on the Berliner Lebensqualitätsprofil, the German version of the Lancashire Quality of Life Profile, and also the average score in the domain 'living situation' $(p<.01)$ were significantly higher in group B. The conclusion was that well known psychological mechanisms like 'acquiescence' (Messick, 1967) and 'social desirability' (Edwards, 1957) may have had an impact on interview results and led to higher satisfaction when case managers interviewed their own patients. Basic material interests may also have influenced the patients' answers and contributed to the more positive ratings in group B: at least those patients who lived in group homes or hostels and not in their own apartments ( $90 \%$ of the sample) might have been concerned that an expression of dissatisfaction with their life and their living arrangements would jeopardise the current arrangement. They might have believed that saying they were dissatisfied with how they lived would make their case manager look for even less attractive alternative housing so that they would lose their accommodation.

A methodological shortcoming of the study conducted by Kaiser et al. (1998) was the diagnostic mix of the sample (ICD-10: schizophrenia: $62 \%$, alcoholism: 27\%, other: 11\%). Although there were no statistically significant group differences between the diagnostic subgroups, satisfaction scores for alcoholics were lower in nearly all domains.

Because of these limitations of the previous study, this study set out to examine the impact of the relationship between interviewer and interviewee on SQOL ratings in a diagnostically homogeneous sample. Moreover, it was to test whether, and to what extent, the results found in the study cited above can be generalised across different treatment settings. Is it a general rule that neutral interviewers elicit less favourable SQOL ratings than case managers who are in charge of care of the interviewees? If there is a consistent interviewer effect on patients' SQOL ratings, what is its size?

\section{METHODS}

\section{Sample}

Data of schizophrenia patients $(\mathrm{N}=32)$ in the first study (Kaiser et al. 1998) were pooled together with data from a diagnostically homogeneous group of schizophrenia outpatients 
$(\mathrm{N}=52)$ which had also been interviewed using the Berliner Lebensqualitätsprofil. On the questionnaire, satisfaction with life as a whole and with life domains are rated on 7 point Likert type scales with 1 the negative, and 7 the positive extreme. All patients in the latter sample had been randomly selected from an outpatient clinic integrated in a comprehensive community care system run by the Department of Social Psychiatry at the Free University of Berlin (Priebe \& Gruyters, 1995). The care system serves severely mentally ill people between 18 and 65 years of age in an inner city catchment area of 180,000 population (Charlottenburg).

As in the study reported by Kaiser et al. (1998), patients were randomly allocated in two interview conditions: one group was interviewed by their clinical case manager ( 2 social workers and 3 psychiatrists), the other group by research assistants (psychologists) not known to the patients and not involved in treatment.

In all patients, the diagnosis of schizophrenia was made by the clinician psychiatrist according to ICD-10.

Interviews in the sheltered living treatment situation were carried out in the patients homes, group homes or hostels. The outpatient clinic patients were interviewed in the clinic building.

\section{Statistics}

Differences between the two samples in sociodemographic and clinical characteristics were analysed using t-tests and chi-square statistics. Differences in SQOL variables for the pooled data set from the two treatment situations were analysed using two-factorial analyses of variance (ANOVA). Satisfaction with life as a whole and with different life domains as well as SQOL mean values were dependent variables. Since the two samples differed in age and years since first admission these variables were included as covariates in all ANOVAs. Additionally monthly income was added as a covariate for the domain of finances.

The first ANOVA factor was the different interviewer-interviewee relationship (interviewers: $A=$ external researchers unknown to patients, $B=$ case managers in charge of the patient's care). The second factor was the two different treatment situations (sample $\mathbb{I}=$ outpatient clinic and sample $I I=$ sheltered living). We were interested in the first ANOVA main effect concerning the interview conditions and hypothesised that scores in groups B would be more favourable than in groups A. The second main effect (differences between patients of the outpatient clinic and those in sheltered living) was not of special interest as both conditions for treatment and care overlapped in both groups, i.e. some patients in the out-patient clinic (group I) were also in sheltered living arrangements and some of the patients in sheltered living (group II) also attended an out-patient clinic in their district (in the latter group, however, there were different providers for sheltered living and out-patient clinic). Thus a differential effect of the treatment situation on SQOL ratings could not be isolated. However, the interaction effect between interview conditions and treatment situations was of interest. The interaction effect indicates whether main effects differ between settings or can be generalised across interview settings. Additionally we analysed SQOL differences separately for each treatment situation (using one-tailed t-tests) - if there was significant ANOVA main effect, a significant interaction, or both. Interactions diagrams according to Leigh \& Kinnear (1980) are presented. 


\section{RESULTS}

\section{Sample characteristics}

Patients from sheltered living were older than those from the outpatient clinic (see Table 1). They had a lower monthly and earned income (rarely from regular jobs, mostly from sheltered employment) and they had been ill for a longer time. Other data did not differ significantly between the two samples.

\section{Subjective quality of life}

For the pooled data set (see column 'total sample' in Table 2) all satisfaction ratings except the one regarding 'social relations' were higher in interview condition B. We found a) two significant main effects without significant interaction effects: work and living situation, b) two significant interaction effects without significant main effects: family and mental health and c) one significant main and interaction effect at the same time concerning the SQOL mean scores.

a) The case is simple for the domains of work and living situation: for both samples scores are higher in interview situation B although differences do not reach statistical significance in the outpatient clinic sample. Yet, the effects in the sheltered living sample are strong enough to lead to a significant additive effect for the pooled data set.

b) 'Disordinal' interactions can be observed for the domains of family and mental health (see

Table 1

Sample characteristics

\begin{tabular}{|c|c|c|c|c|c|c|}
\hline & \multirow{2}{*}{\multicolumn{2}{|c|}{$\begin{array}{c}\text { Total Sample } \\
\mathrm{N}=78 \\
\end{array}$}} & \multirow{2}{*}{\multicolumn{2}{|c|}{$\begin{array}{c}\text { Subsample } 1 \\
\text { Outpatient clinic } \\
\mathbb{N}=46 \\
\end{array}$}} & \multirow{2}{*}{\multicolumn{2}{|c|}{$\begin{array}{c}\text { Sulbsample II } \\
\text { Slueltered living } \\
\mathbf{N}=\mathbf{3 2}\end{array}$}} \\
\hline & & & & & & \\
\hline & Mean & $\mathrm{SD}$ & Mean & $\mathrm{SD}$ & Mean & $\mathrm{SD}$ \\
\hline Age in years ${ }^{1}$ & 44,5 & 11,3 & 41,9 & 11,0 & 48,3 & 10,8 \\
\hline $\begin{array}{l}\text { Monthly income (DM) } \\
\text { Earned income }(\mathrm{DM})^{3} \\
\text { Years since } 1 \text { st admission to a psychiatric hospital }{ }^{4}\end{array}$ & $\begin{array}{c}1065 \\
712 \\
16,4\end{array}$ & $\begin{array}{l}511 \\
738 \\
10,5\end{array}$ & $\begin{array}{l}1190 \\
1058 \\
13,0\end{array}$ & $\begin{array}{l}479 \\
737 \\
7,7\end{array}$ & $\begin{array}{l}890 \\
269 \\
21,4\end{array}$ & $\begin{array}{l}510 \\
459 \\
12,1\end{array}$ \\
\hline Years since 1 st admission to a psychiatric hospital ${ }^{4}$ & $\mathrm{~N}$ & Percent & $\mathbf{N}$ & Percent & $\mathrm{N}$ & Percent \\
\hline Women & 40 & $51 \%$ & 21 & $46 \%$ & 19 & $59 \%$ \\
\hline $\begin{array}{l}\text { Marital status } \\
\text { Single } \\
\text { Married/cohabiting } \\
\text { Separated/divorced/widowed }\end{array}$ & $\begin{array}{r}50 \\
8 \\
20\end{array}$ & $\begin{array}{l}64 \% \\
10 \% \\
26 \%\end{array}$ & $\begin{array}{r}30 \\
6 \\
12\end{array}$ & $\begin{array}{l}65 \% \\
13 \% \\
22 \%\end{array}$ & $\begin{array}{r}20 \\
2 \\
10\end{array}$ & $\begin{array}{r}63 \% \\
6 \% \\
21 \%\end{array}$ \\
\hline $\begin{array}{l}\text { Has a job (incl. sheltered employment or industrial } \\
\text { therapy) }\end{array}$ & 34 & $44 \%$ & 18 & $39 \%$ & 16 & $32 \%$ \\
\hline Psychiatric admission last year & 18 & $23 \%$ & 10 & $22 \%$ & 8 & $25 \%$ \\
\hline
\end{tabular}


Table 2

Subjective Quality of Life

\begin{tabular}{|c|c|c|c|c|c|c|c|c|c|c|c|c|}
\hline \multirow[t]{4}{*}{ Interview conditions } & \multicolumn{4}{|c|}{ Total sample } & \multicolumn{4}{|c|}{$\begin{array}{l}\text { Subsample I: } \\
\text { outpatient clinic }\end{array}$} & \multicolumn{4}{|c|}{$\begin{array}{l}\text { Subsample II: } \\
\text { sheltered living }\end{array}$} \\
\hline & \multicolumn{4}{|c|}{$N=78$} & \multicolumn{4}{|c|}{$\mathbb{N}=46$} & \multicolumn{4}{|c|}{$\mathbb{N}=32$} \\
\hline & \multicolumn{2}{|c|}{ A } & \multicolumn{2}{|c|}{ B } & \multicolumn{2}{|c|}{ A } & \multicolumn{2}{|c|}{ B } & \multicolumn{2}{|c|}{ A } & \multicolumn{2}{|c|}{$\mathbb{B}$} \\
\hline & Mean & $\mathrm{SD}$ & Mean & $\mathrm{SD}$ & Mean & $\mathrm{SD}$ & Mean & SD & Mean & SD & Mean & $\mathrm{SD}$ \\
\hline General well-being & 4,84 & 1,27 & 4,89 & 1,21 & 4,72 & 1,14 & 4,65 & 1,37 & 5,00 & 1,46 & 5,23 & 0,87 \\
\hline Domains & & & & & & & & & & & & \\
\hline Work $^{1,6}$ & 4,58 & 1,53 & 5,28 & 1,32 & 4,72 & 1,09 & 5,09 & 1,20 & 4,38 & 2,03 & 5,55 & 1,47 \\
\hline Leisure & 4,78 & 1,36 & 4,94 & 1,28 & 4,54 & 1,13 & 4,54 & 1,11 & 5,13 & 1,61 & 5,50 & 1,33 \\
\hline Finances & 3,90 & 1,70 & 4,62 & 2,06 & 4,17 & 1,75 & 4,39 & 2,04 & 3,50 & 1,59 & 4,94 & 2,11 \\
\hline Living situation $^{2.7}$ & 4,51 & 1,89 & 5,13 & 1,56 & 4,52 & 1,83 & 4,78 & 1,73 & 4,50 & 2,03 & 5,63 & 1,15 \\
\hline Safety & 4,90 & 1,31 & 5,10 & 1,21 & 4,85 & 1,20 & 4,98 & 1,13 & 4,97 & 1,50 & 5,28 & 1,34 \\
\hline Family $^{3}$ & 4,91 & 1,44 & 4,99 & 1,61 & 5,15 & 0,99 & 4,60 & 1,72 & 4,55 & 1,89 & 5,55 & 1,27 \\
\hline Social relations & 4,94 & 1,20 & 4,78 & 1,30 & 4,89 & 1,19 & 4,46 & 1,10 & 5,00 & 1,25 & 5,26 & 1,46 \\
\hline Mental health ${ }^{4,8}$ & 4,41 & 1,60 & 4,44 & 1,52 & 4,57 & 1,34 & 3,78 & 1,35 & 4,19 & 1,94 & 5,40 & 1,24 \\
\hline $\begin{array}{l}\text { Mean score } \\
\text { (whole profile) })^{5,9}\end{array}$ & 4,64 & 0,91 & 4,91 & 0,84 & 4,68 & 0,90 & 4,59 & 0,68 & 4,58 & 0,96 & 5,37 & 0,86 \\
\hline
\end{tabular}

Total sample: ANOVA-results (main effects: one-tailed)

${ }^{1}$ Main effect: $\quad F=6,12 / p=.008{ }^{2}$ main effect: $\quad F=2,92 / p=.046{ }^{3}$ Interaction effect: $F=4,30$ / $p=.042{ }^{4}$ interaction effect: $F=8,06 / p=.006{ }^{5}$ Main effect: $F=2,90 / p=.046$; interaction effect: $F=$ $4,34 / \mathrm{p}=.041$

Differences within sample I and II: t-tests (one tailed)

${ }^{6}$ II: $\mathrm{t}=-1,87 / \mathrm{p}=.036{ }^{7}$ II: $\mathrm{t}=-1,93 / \mathrm{p}=.032{ }^{8} \mathrm{I}: \mathrm{t}=1,97 / \mathrm{p}=.027 ;$ II: $\mathrm{t}=-2,10 / \mathrm{p}=.022 \quad{ }^{9} \mathrm{II}: \mathrm{t}=$ $2,46 / \mathrm{p}=.010$

Figure 1). For these two variables the effects of one group are strong enough to suppress the other groups' inverse differences effects, which are in opposite directions for the two groups - non-significant for the domain family and significant in both groups for mental health (see Table 2).

c) For SQOL mean scores the partially opposite tendencies in the two treatment situations lead to the following results: Figure 1(a) shows a significant interaction that again has to be classified as 'disordinal' according to Leigh and Kinnear (1980). That means that the significant main effect for the pooled data set can not be interpreted across treatment situations. Interview condition B is superior to A only for sample II - although strong enough to override the partially inverse relationships for sample $I$.

\section{DISCUSSION}

This study examined whether a domain specific (living situation) and overall interviewer effect (referring to the mean scores) on SQOL ratings, which had been found in a previous study in a diagnostically heterogeneous group (Kaiser et al. 1998), was replicated in a bigger and diagnostically homogeneous group of schizophrenia patients across different settings. The two settings studied (sheltered living and an outpatient clinic) are components 

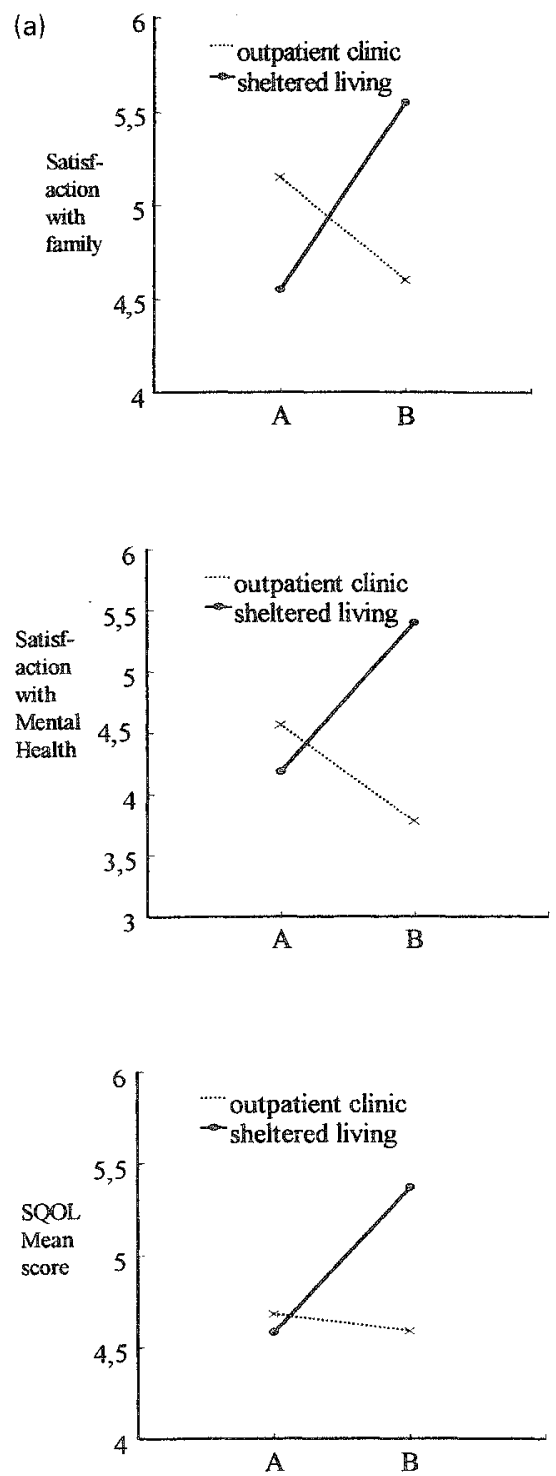

Figure 1. Interaction diagrams: interview conditions $x$ treatment situations. Ia Interview condition: $A=$ external researcher vs $\mathbf{B}=$ case manager. 1b Treatment situation: outpatient clinic vs sheltered living

of a similar community oriented approach and are situated in two neighbouring districts of the same city.

We found some differences between the two interview situations. Most of the differences failed to reach statistical significance because of the high variance of ratings and of the 

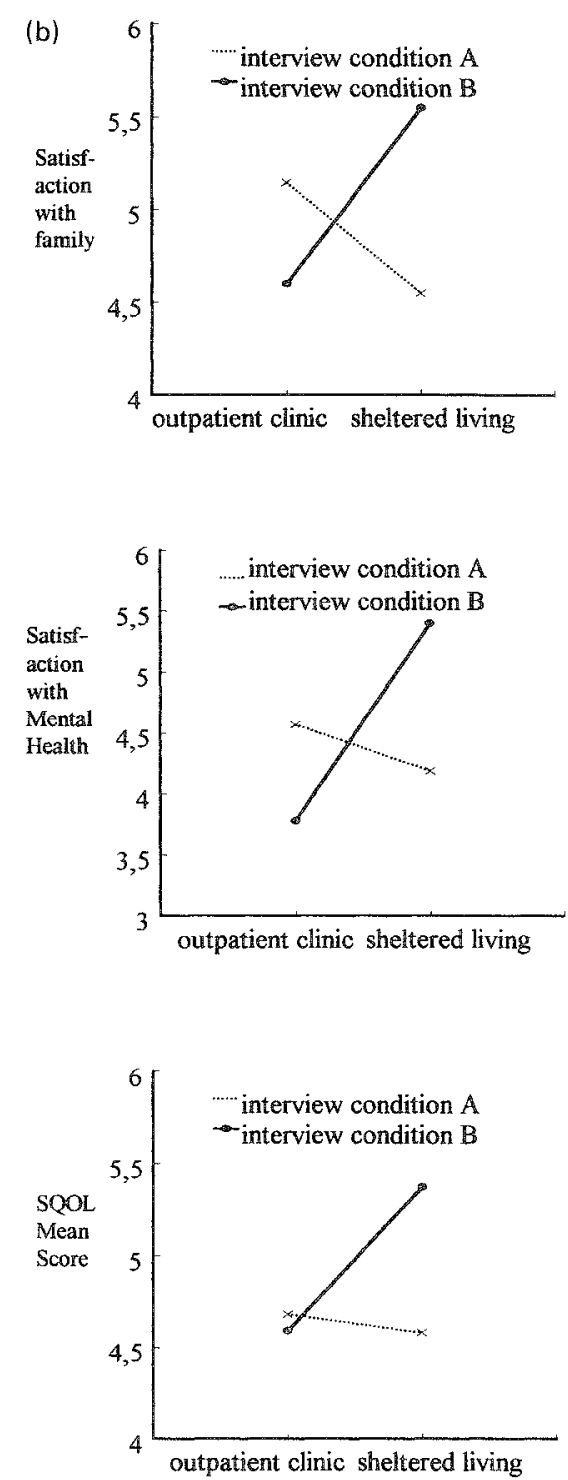

Figure 1. Interaction diagrams: interview conditions $\mathrm{x}$ treatment situations. 1 a 耳terview condition: $A=$ external researcher vs $\mathbb{B}=$ case manager. $1 \mathrm{~b}$ Treatment situation: outpatient clinic vs sheltered living

relatively small sample size in each sub group. Yet, some differences were statistically significant, and their size appears substantial. For example, in the sheltered living sample the SQOL mean score, which is based on 7 point rating scales, was 0.8 scale points higher when patients were interviewed by their case managers. This difference is clearly bigger than the 
effect that has been achieved in most intervention studies aimed at improving patients' quality of life. The findings underscore the relevance of the interviewer-interviewee relationship on SQOL ratings in schizophrenia patients.

In the pooled data set there was a difference between the two interview situations in satisfaction ratings in two central domains - a work and living situation. In these domains, ratings in both samples were more positive when patients were interviewed by their case managers. The effects were stronger and reached statistical significance in the sheltered living sample. Satisfaction ratings with three domains yielded discordant interaction effects, i.e. differences in opposite directions in the two settings (significant: family and mental health, non-significant: social relations). For patients in sheltered living, these domains may be viewed as separate from their care and not influenced by their case managers. Thus, they might generalise their overall tendency for more positive ratings to all domains if case-managers are interviewers. In the out-patient clinic, however, patients might associate the domains of mental health - and to a lesser extent family and social relations - more closely with treatment and with the commitment and efforts of their clinical case managers. In these more treatment related domains - but in no other domain - patients in the out-patient clinic expressed less satisfaction when interviewed by their case managers. This may be regarded as an objective cognitive dissonance (Festinger \& Carlsmith, 1959) reflecting the patients' wish to optimise psychiatric treatment. It might also be interpreted as a Hawthorneeffect (Roethlisberger \& Dickson, 1964). Patients in a model institution of community care (sample I) may give more positive ratings to researchers regarding domains that can be seen as primary targets not of psychiatric treatment, but of this special institution's approach which is distinct from what they have experienced in other institutions before.

These interpretations are extremely speculative. Independently of these interpretations, however, the study has found answers to the question it was set out to address. There may be an effect of the interviewer-interviewee relationship on SQOL ratings in different settings. This effect seems to be setting and group specific. There is no consistent size and not even a consistent direction of the effect. On average, patients with schizophrenia in community care settings seem to express a more positive SQOL when interviewed by their case managers as opposed to external researchers. The size of the difference is, on average, limited. In special circumstances, the difference may be reversed and independent interviewers elicit more positive SQOL ratings than case managers involved in the patients' care.

It may be concluded that an interviewer effect has to be considered when research studies or routine evaluation using SQOL ratings are planned and when SQOL data are interpreted. The direction and particularly the size of the effect are likely to depend on various characteristics of the setting and of the interview situation. Both direction and size of the effect should be explored in each setting and situation. It appears important that they may vary in different life domains. A consistent, unidirectional and uniform effect of the relationship of interviewer and interviewee on SQOL ratings could not be identified in this study. For future evaluative research studies, an independent researcher as interviewer may still be the preferred option although the generalisability of findings to routine situations remains problematic. If SQOL data have been gathered by independent interviewers, there are good reasons to assume that results would have been different if patients had been interviewed by professional staff in charge of their care. What remains unclear is just 
precisely in which way, to what extent and regarding which domains ratings would have been different.

\section{REFERENCES}

AWAD, A.G. \& VOGURANTI, L.N.P. (1999) Neuroleptics and quality of life in schizophrenia. In Quality of Life and Mental Health Care (eds. S. Priebe, J.P.J. Oliver, W. Kaiser). Petersfield, UK: Wrightson Biomedical Publishing.

CORRIGAN, P.W. \& BUICAN, B. (1995) The construct validity of subjective quality of life for the severely mentally ill. Journal of Nervous and Mental Disease, 186, 281-285.

EDWARDS, L.E. (1957) The Social Desirability Variable in Personality Research. New York: Dryden.

FESTINGER, L. \& CARLSMITH, J.M. (1959) Cognitive consequences of forced compliance. Journal of Abnormal and Social Psychology, 58, 203-210.

HOLLOWAY, F. \& CARSON, J. (1998) Intensive case management for the severely mentally ill. British Journal of Psychiatry, 172, 19-22.

KAISER, W., BUROW, S., DAHMS, M., LUND, H., NAST, J. \& ZINDEL, K. (1998) Interviewereffekte bei der Erhebung subjektiver Lebensqualität und der Zufriedenheit mit der Betreuung im Betreuten Wohnen. Psychiatrische Praxis, 25, 142-148.

KAISER, W. \& PRIEBE, S. (1998) Zur Messung von Veränderungen der subjektiven Lebensqualität bei chronisch schizophrenen Patienten. Nervenarzt, 69, 219-227.

KAISER, W. (1999) Methods for the assessment of quality of life in mental health care. In Quality of Life and Mental Health Care (eds. S. Priebe, J.P.J. Oliver \& W. Kaiser). Petersfield, UK: Wrightson Biomedical Publishing.

LEHMAN, A.F. (1983) The well-being of chronic mental patients: assessing their quality of life. Archives of General Psychiatry, 40, 369-373.

LEHMAN, A.F. (1996) Measures of quality of life among persons with severe and persistent mental disorders. Social Psychiatry and Psychiatric Epidemiology, 31, 78-88.

LEHMAN, A.F., POSSIDENTE, S. \& HAWKER, F. (1986) The quality of life of chronic patients in a state hospital and in community residences. Hospital and Community Psychiatry, 37, 901-907.

LEIGH, J.H. \& KINNEAR, T.C. (1980) On interaction Classification. Educational and Psychological Measurement, 40, 841-843.

MESSICK, S.J. (1967) The psychology of acquiesence: an interpretation of research evidence. In Response Set in Personality Assessment (ed. I.A. Berg). Chicago: Aldine.

OLIVER, J.P.J., HUXLEY, P.J., PRTEBE, S. \& KAISER, W. (1997) Measuring the quality of life of severely mentally ill people using the Lancashire Quality of Life Profile. Social Psychiatry and Psychiatric Epidemiology, 32, 76-83.

PRIEBE, S. \& GRUYTERS, T. (1995) Patients' Assessment of Treatment Predicting Outcome. Schizophrenia Bulletin, 21 (1), 87-94.

PRIEBE, S., OLIVER, J.P.J., KAISER, W. (eds.) (1999) Quality of Life and Mental Health Care. Petersfield, UK: Wrightson Biomedical Publishing

ROETHLISBERGER, F.J. \& DICKSON, W.J. (1964) Management and the Worker. Cambridge, Mass.: Harvard University Press.

RUSSO, J., ROY-BYRNE, P., REEDER, D., ALEXANDER, M., DWYER-O'CONNOR, E., DAGADAKIS, C., RIES, R. \& PATRICK, D. (1997) Longitudinal assessment of quality of life in acute psychiatric inpatients: reliability and validity. Journal of Nervous and Mental Disease, 185, 166-175.

SAINFORT, F., BECKER, M. \& DIAMOND, R. (1996) Judgements of quality of life of individuals with severe mental disorders: patient self-report versus provider perspectives. American Journal of Psychiatry, $153,497-502$.

SKANTZE, K., MALM, U., DENCKER, S.J., MAY, P.R.A. \& CORRIGAN, P. (1992) Comparison of quality of life with standard of living in schizophrenic outpatients. British Journal of Psychiatry, 161, 797-801.

TAYLOR, R., LEESE, M., CLARKSON, P., HOLLOWAY, F, \& THORNICROFT, G. (1998) Quality of life outcomes for intensive versus standard community mental health services. PRiSM Psychosis Study 9. British Journal of Psychiatry, 173, 416-422.

THAPA, K. \& ROWLAND, L.A. (1989) Quality of life in long-term care staff and patient perceptions. Acta Psychiatrica Scandinavica, 80, 267-271. 
VORUGANTI, L., HESLEGRAVE, R., AWAD, G.A. \& SEEMAN, M.V. (1998) Quality of life measurement in schizophrenia: reconciling the quest for subjectivity with the question of reliability. Psychological Medicine, $28,165-172$.

Wolfgang Kaiser, PhD, DiplPsych, Krankenhaus Spandau, Örtlicher Bereich Griesingerstraße, Erwachsenenambulanz, Griesingerstr 27-32, 13589 Berlin. Tel: +49 (0)30 3701 - 4551, Fax: -3505

Stefan Priebe, Professor of Social and Community Psychiatry, MD, DiplPsych, St Bartholomew's and the Royal School of Medicine. Queen Mary and Westfield College. University of London, UK

Correspondence to Dr. Kaiser 